\title{
Injured pancreatic $\beta$ cells enhance the release of miR-375-3p into the extracellular space
}

\author{
MITSURU CHIBA $^{1}$, IKUMI NIIYAMA ${ }^{2}$, HARUKA UEHARA $^{2}$ and HARUKA KUWATA ${ }^{2}$ \\ ${ }^{1}$ Department of Bioscience and Laboratory Medicine, Graduate School of Health Sciences, Hirosaki University; \\ ${ }^{2}$ Department of Medical Technology, School of Health Sciences, Hirosaki University, Hirosaki, Aomori 036-8564, Japan
}

Received August 17, 2018; Accepted January 28, 2019

DOI: $10.3892 /$ etm.2019.7276

\begin{abstract}
R-375-3p is a highly expressed microRNA in pancreatic $\beta$ cells. We have previously reported that when mice were exposed to $7 \mathrm{~Gy}$ X-ray irradiation, miR-375-3p was increased in the serum and there was cytotoxicity in pancreatic $\beta$ cells. However, it was unknown whether miR-375-3p is then released from injured pancreatic $\beta$ cells to the extracellular space. The present study investigated the effect of ionizing radiation and streptozotocin (STZ) treatment on the expression of extracellular miR-375-3p into culture supernatants using the rat pancreatic $\beta$ cell line RIN-5F. Cell growth was reduced, and cell death was increased at $24 \mathrm{~h}$ following exposure to 7 Gy irradiation as well as $24 \mathrm{~h}$ following treatment with $30 \mathrm{mM}$ STZ compared with the control. Expression levels of miR-375-3p were significantly increased $24 \mathrm{~h}$ after $30 \mathrm{mM}$ STZ treatment, yet this was only observed at $48 \mathrm{~h}$ following exposure to $7 \mathrm{~Gy}$ compared with the control. This suggests that the mechanism of cell death in RIN-5F is different between 7 Gy irradiation and $30 \mathrm{mM} \mathrm{STZ}$ treatment. The results of the present study suggest that injured pancreatic $\beta$ cells enhance the release of miR-375-3p from cells into extracellular space.
\end{abstract}

\section{Introduction}

MicroRNAs (miRNAs) are small (18-25 nucleotides) non-coding RNA harboring a post-transcriptional gene regulatory function (1). Currently, miRNAs have been detected in various body fluids, including serum (2), plasma (3), urine (4), cerebrospinal fluid (5), breast milk (6), saliva (7), bronchoalveolar lavage fluid (8), ascites (9), and pleural effusion (10). Noteworthy, miRNAs are stable under non-physiological conditions, whether in body fluids or culture media.

Correspondence to: Dr Mitsuru Chiba, Department of Bioscience and Laboratory Medicine, Graduate School of Health Sciences, Hirosaki University, 66-1 Hon-cho, Hirosaki, Aomori 036-8564, Japan

E-mail: mchiba32@hirosaki-u.ac.jp

Key words: miR-375-3p, pancreatic $\beta$ cells, cell death, ionizing radiation, streptozotocin, extracellular vesicles
Taylor et al (11) reported that plasma miR-21 is stable for at least 28 days at $-30^{\circ} \mathrm{C}$. We have reported that extracellular small RNAs are stable for 4 weeks at room temperature, after 20 freeze-thaw cycles and exposure to $\mathrm{pH} 2.0$, and are resistant to ribonuclease A degradation (12). In body fluids, miRNAs are present in extracellular vesicles (EVs) (13) or high-density lipoproteins (14) and bind RNA-binding proteins (15). They are proposed to become novel biomarkers of disorders including some cancers and neurodegenerative diseases.

miR-375-3p is expressed in pancreatic $\beta$ cells (16), where this miRNA is involved in pancreatic development, $\beta$ cell proliferation, and insulin secretion via gene regulation (17). Overexpression of miR-375-3p suppresses insulin secretion (18), whereas inhibition of endogenous miR-375-3p increases insulin secretion (19). Streptozotocin (STZ) is a nitrosourea alkylating agent that induces tumor shrinkage and hypoglycemia and causes the selective destruction of pancreatic $\beta$ cells via a glucose transporter 2 (20). Therefore, STZ have been used as a therapeutic drug for the treatment of neuroendocrine tumors in Japan (21). In mice and rats, the administration of STZ induces diabetes after pancreatic $\beta$ cells are injured $(22,23)$. Erener et al (24) reported that blood miR-375-3p increased in STZ-treated mice.

We have previously shown that mice irradiated with a lethal X-ray dose of 7 Gy present a significant serum increase of miR-375-3p at $72 \mathrm{~h}$ after exposure (2). Since miR-375-3p is expressed the highest in the pancreas among 20 types of cells and organs examined, it was inferred that it derived from the pancreas. This research suggested that radiation-induced death of pancreatic $\beta$ cells is associated with the release of EVs containing miR-375-3p. Although miR-375-3p is expected to be released from injured pancreatic $\beta$ cells, no evidence has been obtained. Therefore, it is necessary to investigate whether miR-375-3p is released from cells by STZ treatment and 7 Gy $\mathrm{X}$-ray irradiation, which is a different mechanism to injure pancreatic $\beta$-cells. In this study, we investigate the expression level of extracellular miR-375-3p released from an insulinoma cell line exposed to 7 Gy X-ray irradiation or STZ treatment.

\section{Materials and methods}

Cell line and culture. The rat pancreatic $\beta$ cell line (RIN-5F) was purchased from the American Type Culture Collection (ATCC, Manassas, VA, USA). RIN-5F cells were cultured 
in RPMI-1640 medium (Wako, Tokyo, Japan) supplemented with $10 \%$ fetal bovine serum (Thermo Fisher Scientific, Inc., Waltham, MA, USA), $100 \mathrm{U} / \mathrm{ml}$ of penicillin, and $100 \mu \mathrm{g} / \mathrm{ml}$ of streptomycin (Wako). Cells were cultured at $37^{\circ} \mathrm{C}$ in a humidified atmosphere with $5 \% \mathrm{CO}_{2}$.

$X$-ray irradiation. RIN-5F cells were exposed to X-rays (MBR-1520R-3 X-ray machine, Hitachi Medical Corporation, Tokyo, Japan) at a dose rate of $1.0 \mathrm{~Gy} / \mathrm{min}(150 \mathrm{kVp}, 20 \mathrm{~mA}$, 0.5 -mm aluminum, and $0.3-\mathrm{mm}$ copper filters).

STZ treatment. STZ and Dulbecco's phosphate-buffered saline [D-PBS(-), pH 7.2] were purchased from Wako. STZ was diluted in D-PBS(-).

RNA extraction. Total RNAs from RIN-5F cells were extracted using Isogen II reagents (Nippongene, Tokyo, Japan) according to the manufacturer's instruction. Cell culture medium samples were centrifuged at $300 \mathrm{xg}$ at $4^{\circ} \mathrm{C}$ for $3 \mathrm{~min}$ and floating cells removed. Total RNAs from $200 \mu \mathrm{l}$ culture supernatants added to $5 \mu 1$ cel-miR-39 $(1 \mathrm{nM})$ were extracted using Isogen II reagents and ethachinmate (Nippongene).

Reverse transcription quantitative polymerase chain reaction (RT-qPCR). The expression of rat insulin 1 (Ins 1) and $\beta$ actin (Actb) mRNAs in RIN-5F cells were determined by RT-qPCR . Briefly, total RNAs were isolated from RIN-5F cells. cDNA was synthesized from total RNA using the Applied Biosystems ${ }^{\mathrm{TM}}$ High Capacity cDNA Reverse Transcription kit (Thermo Fisher Scientific, Inc.), according to the manufacturer's instructions. qPCR was performed using a FastStart Universal SYBR Green Master (Roche Diagnostics, Basel, Switzerland), $10 \mu \mathrm{M}$ of forward and reverse primer pairs (Table I), and the StepOne Plus Real-time PCR system (Thermo Fisher Scientific, Inc.) in the following conditions: $10 \mathrm{~min}$ at $95^{\circ} \mathrm{C}$, followed by 40 cycles each of $95^{\circ} \mathrm{C}$ for $15 \mathrm{sec}$, and $60^{\circ} \mathrm{C}$ for $60 \mathrm{sec}$. Actb was used as internal control. The PCR products were separated by electrophoresis on $4 \%$ agarose gel and detected by ethidium bromide staining.

RT-qPCR was used to determine the expression levels of miR-375-3p in culture supernatants. The cDNAs were synthesized using the TaqMan ${ }^{\mathrm{TM}}$ miRNA RT kit and the prescribed $5 \times$ RT primer (both from Thermo Fisher Scientific, Inc.) according to the manufacturer's instructions. qPCR for miRNAs was performed using a FastStart TaqMan probe master (Roche Diagnostics), a $20 \mathrm{x}$ probe, and the StepOne Plus Real-Time PCR system (Thermo Fisher Scientific, Inc.) under the following conditions: $10 \mathrm{~min}$ at $95^{\circ} \mathrm{C}$, followed by 45 cycles at $95^{\circ} \mathrm{C}$ for $15 \mathrm{sec}$, and $60^{\circ} \mathrm{C}$ for $60 \mathrm{sec}$. Cel-miR-39 was used as an external control. The comparative $\mathrm{Ct}$ method was used to determine expression levels.

Immunofluorescence staining. Immunofluorescence staining was performed for detection of insulin in RIN-5F cells. RIN-5F cells were plated in 8 -well chamber slides at a density of $2 \times 10^{4}$ cells per well in culture media. After $48 \mathrm{~h}$, the cells were washed three times with D-PBS(-) and treated with $0.2 \%$ Triton X-100 in D-PBS(-) at room temperature for $5 \mathrm{~min}$. After washing three times in D-PBS(-), the cells were incubated in an Image-iT FX signal enhancer solution
(Thermo Fisher Scientific, Inc.) at room temperature for $30 \mathrm{~min}$. Next, the cells were incubated with a primary rabbit monoclonal antibody raised against insulin (C27C9) (no. 3014; Cell Signaling Technology, Inc., Danvers, MA, USA) at 1:100 dilution in Immunostain Solution A (Toyobo, Osaka, Japan) at room temperature for $60 \mathrm{~min}$. After five times washing with D-PBS(-), cells were incubated at room temperature for 60 min with an anti-rabbit IgG Alexa Fluor 488-conjugated secondary antibody (no. 4412; Cell Signaling Technology, Inc.) at 1:200 dilution in Immunostain Solution B. The cells were washed five times with D-PBS(-), and the nuclei were stained with 4',6-diamidino-2-phenylindole (DAPI) in ProLong Gold Antifade Reagent (Thermo Fisher Scientific, Inc.). The cells were visualized under a confocal laser scanning microscope LSM710 (Carl Zeiss, Oberkochen, Germany).

Flow cytometry. RIN-5F cells were plated on $3-\mathrm{cm}$ dishes at a density of $2 \times 10^{6}$ cells per dish in culture medium. After $96 \mathrm{~h}$, culture medium was discarded, the cells were washed three times in D-PBS(-), and $10 \mathrm{ml}$ culture medium was added to each dish. Then, RIN-5F cells were exposed to none or 7 Gy of X-rays at a dose rate of $1.0 \mathrm{~Gy} / \mathrm{min}$ and treated with STZ of a concentration of $0,1,3,10$, or $30 \mathrm{mM}$. The RIN-5F cells were collected and were stained by propidium iodide (PI) solution. PI-positive cells were detected using a Cytomics FC500 (Beckman Coulter, Brea, CA, USA).

Cell proliferation assay. RIN-5F cells were seeded at the density of $2 \times 10^{4}$ cells per well of a 96 -well flat-bottomed microplate. After pre-culture for $48 \mathrm{~h}$, media were discarded and the cells washed with D-PBS(-). The cells were incubated with STZ diluted in medium at various concentrations $(0,1,3$, 10 , or $30 \mathrm{mM}$ ) for 0,24 , or $48 \mathrm{~h}$. The cells irradiated with $7 \mathrm{~Gy}$ of X-rays and control cells not irradiated were cultured for 0 , 24,48 , or $72 \mathrm{~h}$ after irradiation. Viable cells were detected using the alamarBlue ${ }^{\circledR}$ cell viability reagent (Thermo Fisher Scientific, Inc.) according to the manufacturer's instructions. The fluorescence intensity was measured after $6 \mathrm{~h}$ at an excitation wavelength of $544 \mathrm{~nm}$ and an emission wavelength of $590 \mathrm{~nm}$ using a Fluoroskan Ascent ${ }^{\mathrm{TM}}$ system (Thermo Fisher Scientific, Inc.).

Statistical analysis. Statcel 3 software (OMS Publishing Inc., Saitama, Japan) was used to perform all statistical analyses. Student's t-test was performed to compare the results of the two groups. One-way analysis of variance (ANOVA) was performed followed by Tukey-Kramer multiple comparisons test. $\mathrm{P}<0.05$ was considered to indicate a statistically significant difference.

\section{Results}

RIN-5F cells express insulin. To confirm the pancreatic $\beta$ cells characteristics of RIN-5F cells, the expression of insulin mRNA was determined by RT-qPCR. Both Insl and Actb mRNAs were detected (Fig. 1A). In addition, insulin proteins were detected in RIN-5F cells by immunofluorescence analysis using confocal laser scanning microscopy (Fig. 1B). These results indicate that RIN-5F cells expressing insulin process characteristics of pancreatic $\beta$ cells. 
Table I. Primers for reverse transcription-polymerase chain reaction.

\begin{tabular}{|c|c|c|c|c|}
\hline Primer name & Accession no. & Sequence $\left(5^{\prime}-3^{\prime}\right)$ & Size (nt) & Amplicon size (bp) \\
\hline Ins 1 forward primer & NM_019129.3 & TCATAGACCATCAGCAAGCAG & 21 & 95 \\
\hline Ins 1 reverse primer & & CTTGGGCTCCCAGAGGAC & 18 & \\
\hline Actb forward primer & NM_031144.3 & CCCGCGAGTACAACCTTCT & 19 & 72 \\
\hline$A c t b$ reverse primer & & CGTCATCCATGGCGAACT & 18 & \\
\hline
\end{tabular}
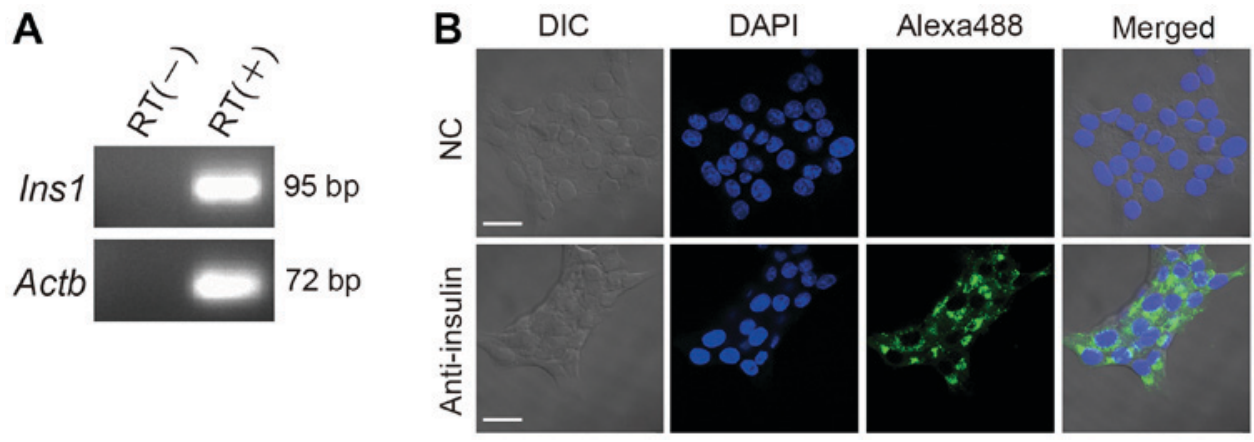

Figure 1. The expression of insulin in RIN-5F cells. (A) The expression of Ins1 and Actb mRNAs determined by RT-qPCR. PCRs with or without reverse transcription (RT) were performed in the RT-qPCR reaction mixture for amplification of Ins 1 and Actb mRNAs using total RNA from RIN-5F cells and the primer pair that does not allow amplification of fragments from the genomic DNA. The PCR products were separated by electrophoresis on $4 \%$ agarose gel and detected by ethidium bromide staining. RT(-) was performed to examine the amplification from template RNA and/or genomic DNA. (B) Representative immunofluorescence image of insulin in RIN-5F cells. Green, Insulin; Blue, Nuclei. Scale bar represents $100 \mu \mathrm{m}$. RT, reverse transcription; DIC, differential interference contrast; DAPI, 4',6-diamidino-2-phenylindole; NC, negative control.

$X$-ray irradiation and $S T Z$ treatment suppress cell proliferation in RIN-5F cells. To assess the sensitivity of RIN-5F cells to irradiation and STZ treatment, a cell proliferation assay was performed. Cell proliferation of RIN-5F cells was significantly suppressed at 24,48 , and 72 h after 7 Gy irradiation (Fig. 2A) and by treatment of 10 or $30 \mathrm{mM} \mathrm{STZ}$ at $24 \mathrm{~h}$ (Fig. 2B) compared with controls. These results indicate that cells exposed to 7 Gy irradiation and high concentration of STZ cannot further proliferate.

$X$-ray irradiation and $S T Z$ treatment induce cell death in RIN-5F cells. To evaluate cell death induced by 7 Gy irradiation or STZ treatment in RIN-5F cells, we performed a flow cytometry analysis in PI-stained RIN-5F cells. The number of PI-positive cells significantly increased at 24, 48, and $72 \mathrm{~h}$ after 7 Gy irradiation compared with non-irradiated (0 Gy) cells (Fig. 3A). PI-positive cells were significantly increased at $24 \mathrm{~h}$ after treatment with $30 \mathrm{mM} \mathrm{STZ}$ and at $48 \mathrm{~h}$ after treatment with 3,10 , or $30 \mathrm{mM} \mathrm{STZ} \mathrm{compared} \mathrm{with} \mathrm{control} \mathrm{cells}$ (Fig. 3B). These results indicate that within $24 \mathrm{~h}$, cell death is induced in RIN-5F cells either exposed to 7 Gy irradiation or $30 \mathrm{mM}$ STZ treatment.

$X$-ray irradiation and $S T Z$ treatment enhance the release of miR-375-3p in RIN-5F cells. To examine the impairmentassociated release of miR-375-3p from RIN-5F cells, we performed RT-qPCR on culture supernatants of RIN-5F cells that were exposed to 7 Gy irradiation or STZ treatment. The expression of miR-375-3p increased significantly at 48 or $72 \mathrm{~h}$ after 7 Gy irradiation (Fig. 4A) and at 24 or $48 \mathrm{~h}$ after treatment of $30 \mathrm{mM}$ STZ compared with control supernatants (Fig. 4B). These results suggest that $7 \mathrm{~Gy}$ irradiation and STZ treatment trigger the release of miR-375-3p from RIN-5F cells into cell culture supernatants.

\section{Discussion}

We have previously shown that miR-375-3p increases in the serum of mice exposed to $7 \mathrm{~Gy}$ X-rays causing cytotoxicity in pancreatic $\beta$ cells (2). However, the direct relationship between miR-375-3p level increases in the blood and the cytotoxicity caused by 7 Gy irradiation remained to be clarified. In this study, employing an in vitro cell culture model of pancreatic $\beta$ cells, we investigated the direct release of miR375-3p from damaged cells.

First, we confirmed that RIN-5F cells have traits characteristics of pancreatic $\beta$ cells. Pancreatic $\beta$ cells are insulin-producing cells and are known to express miR-375-3p (16). The expression of insulin mRNA was confirmed by RT-PCR, and insulin was detected by fluorescent immunostaining (Fig. 1). In this study, RIN-5F cells had traits of pancreatic $\beta$ cells including expression of insulin.

Next, we investigated the effects of 7 Gy X-ray irradiation on cell proliferation and cell death in RIN-5F cells. The suppression of cell proliferation and the increase of PI-positive cells were observed at $24 \mathrm{~h}$ after irradiation (Figs. 2A and 3A). Although the expression of extracellular miR-375-3p was not significantly different after $24 \mathrm{~h}$ of irradiation, it was significantly increased after 48 and $72 \mathrm{~h}$ (Fig. 4A), suggesting that miR-375-3p requires over $24 \mathrm{~h}$ after irradiation to be released in the medium. On the other hand, $30 \mathrm{mM} \mathrm{STZ} \mathrm{treatment}$ inhibited cell proliferation and increased cell death at 24 or $48 \mathrm{~h}$, when treated with $30 \mathrm{mM} \mathrm{STZ}$ (Figs. 2B and 3B), and the expression of extracellular miR-375-3p was concomitantly and 
A

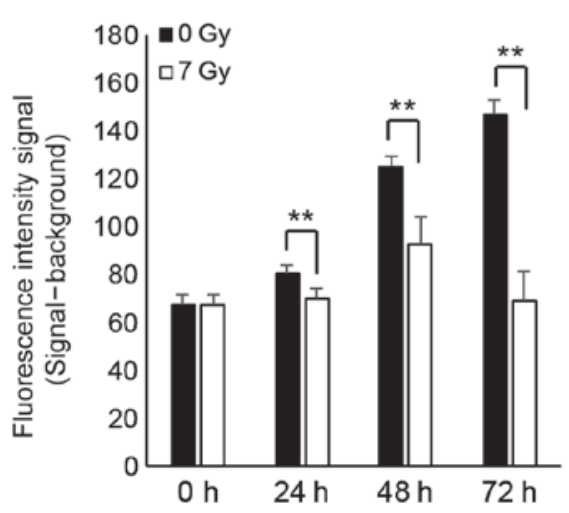

B

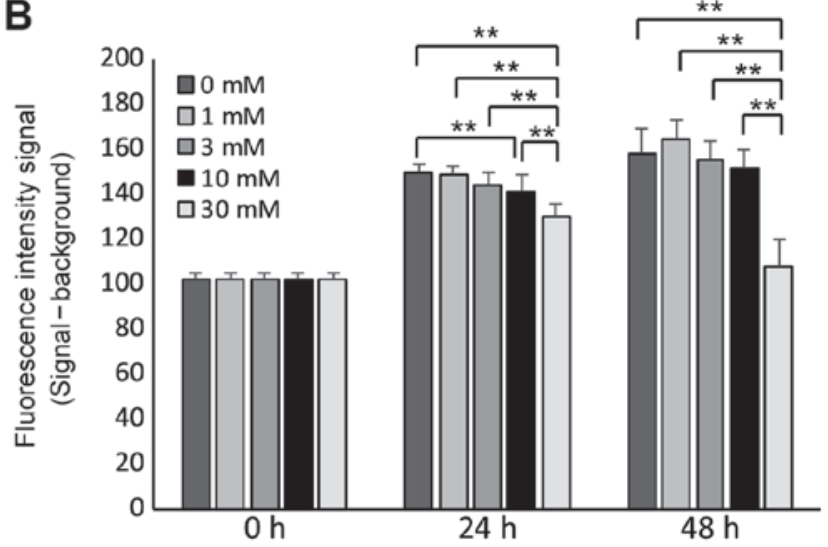

Figure 2. The effects of X-ray irradiation and STZ treatment on cell proliferation in RIN-5F cells. Cell proliferation assay was performed using an alamarBlue cell viability reagent. (A) Cell proliferation profiles after 0 and $7 \mathrm{~Gy}$ irradiation. Statistical comparisons were determined using Student's t-test. ${ }^{* *} \mathrm{P}<0.01$. (B) Cell proliferation profiles after treatment with 0, 1,3, 10, and $30 \mathrm{mM} \mathrm{STZ.} \mathrm{The} \mathrm{horizontal} \mathrm{axis} \mathrm{represents} \mathrm{time} \mathrm{after} \mathrm{irradiation} \mathrm{or} \mathrm{treatment} \mathrm{(h),} \mathrm{whereas} \mathrm{the}$ vertical axis represents fluorescence intensity (Excitation, $544 \mathrm{~nm}$; Emission, $590 \mathrm{~nm}$ ). Statistical comparisons were determined using the one-way ANOVA with Tukey's multiple comparisons. ${ }^{* *} \mathrm{P}<0.01$. All bars, mean \pm standard deviations. Each 8 sample was used.

A

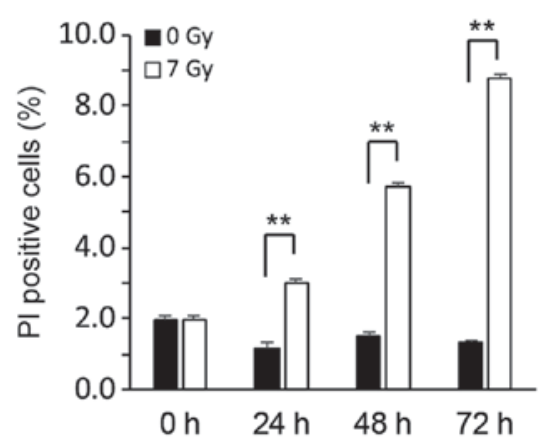

B

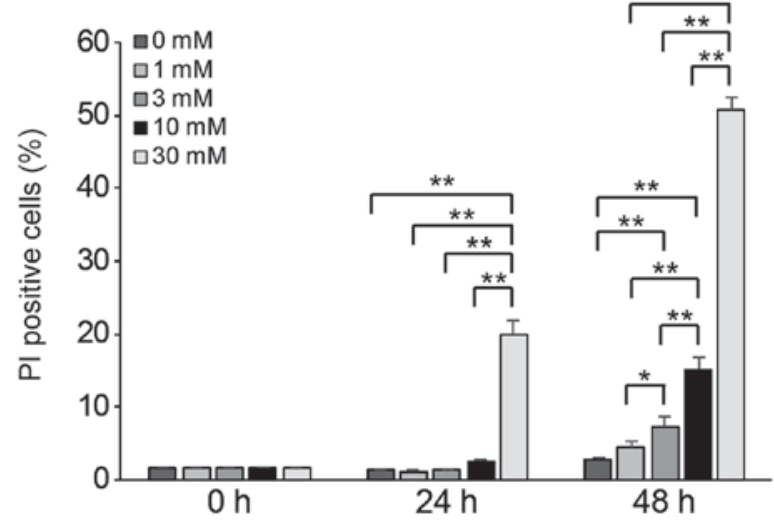

Figure 3. The effects of X-ray irradiation or STZ treatment on cell death in RIN-5F cells. (A) Cell death detection by PI-positive RIN-5F cell quantification following 0 and $7 \mathrm{~Gy}$ irradiation. Statistical comparisons were determined using Student's t-test. ${ }^{* *} \mathrm{P}<0.01$. (B) Cell death detection by PI-positive RIN-5F cell quantification following $0,1,3,10$ and $30 \mathrm{mM}$ STZ treatment. Statistical comparisons were determined using the one-way ANOVA with Tukey's multiple comparisons. " $\mathrm{P}<0.05$ and ${ }^{* *} \mathrm{P}<0.01$. All bars, mean \pm standard deviations. Each 4 sample was used. PI-positive RIN-5F cells were quantified using Cytomics FC500 (Beckman Coulter). The horizontal axis represents time after irradiation or treatment (h), whereas the vertical axis represents the rate of PI-positive cells within a gate $(\%)$.

A

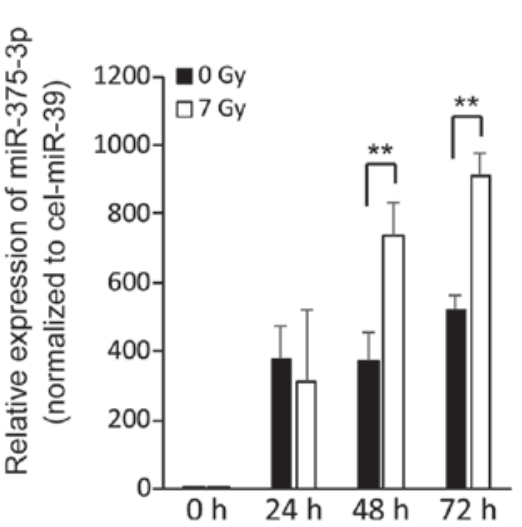

B

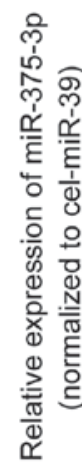

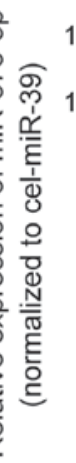

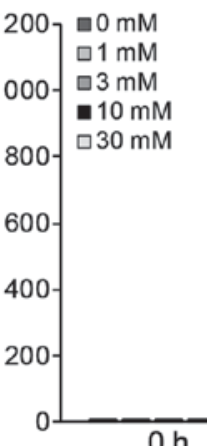

$0 \mathrm{~h}$
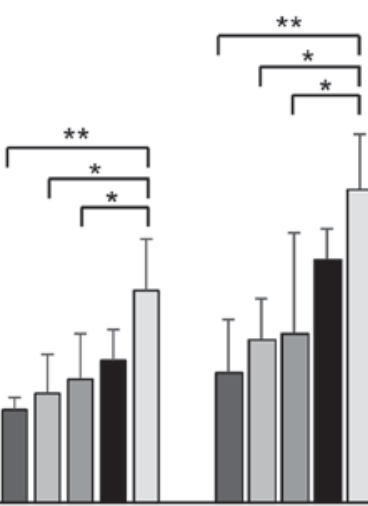

$24 \mathrm{~h}$

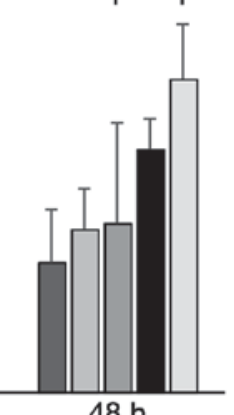

$48 \mathrm{~h}$

Figure 4. The effects of X-ray irradiation and STZ treatment on miR-375-3p released from RIN-5F cells. (A) The expression of miR-375-3p in culture supernatants of RIN-5F cells after 0 and 7 Gy irradiation. Statistical comparisons were determined using Student's t-test. ${ }^{* *} \mathrm{P}<0.01$. (B) The expression of miR-375-3p in culture supernatants of RIN-5F cells treated with 0, 1, 3, 10, and $30 \mathrm{mM}$ STZ. Statistical comparisons were determined using the one-way ANOVA with Tukey's multiple comparisons. ${ }^{*} \mathrm{P}<0.05$ and ${ }^{* *} \mathrm{P}<0.01$. All bars, mean \pm standard deviations. Each 4 sample was used. The expression of miR-375-3p in culture supernatants of RIN-5F cells were determined by RT-qPCR. The horizontal axis represents time after irradiation or treatment (h), whereas the vertical axis represents relative expression of miR-375-3p. Cel-miR-39 was used for as an external control. 
significantly increased at these times (Fig. 4B). Therefore, the mechanism of miR-375-3p release may be different after X-ray irradiation compared with after STZ treatment.

STZ causes the selective destruction of pancreatic $\beta$ cells via a glucose transporter 2 (20). The release of miR-375-3p from cellular to extracellular space is enhanced by the treatment of STZ $(22,23)$. Therefore, STZ have been used as a therapeutic drug for the treatment of insulinoma (21). We propose that the miR-375-3p increase in blood is due to leakage from damaged pancreatic $\beta$ cells caused by STZ. High-dose irradiation induces a programmed cell death called apoptosis (25). Apoptotic cell death minimizes leakage of cell contents by forming EVs such as apoptotic bodies (26). In Fig. 4A, extracellular miR-375-3p did not increase at $24 \mathrm{~h}$ after $7 \mathrm{~Gy}$ irradiation compared with control probably due to cell death by apoptosis. To clarify whether extracellular miR-375-3p is contained in EVs such as apoptotic bodies of culture supernatant after X-ray irradiation and STZ treatment, we aim to analyze in detail apoptosis and EV contents following $\mathrm{X}$-ray irradiation and STZ treatment in the future.

In this study, we clarified that pancreatic $\beta$-cell injury induced an extracellular miR-375-3p increase. PI is only taken up by the cell when the membrane is damaged and decreased metabolism, and binds to the nuclear DNA. Therefore, cells undergoing late apoptosis or necrosis can be detected with PI. In the future, it is necessary to assess the degree of membrane injury using Annexin $\mathrm{V}$ staining binding to membrane phospholipid.

\section{Acknowledgements}

Not applicable.

\section{Funding}

This work was supported in part by JSPS KAKENHI (grant nos. JP25670264, JP17H04761, and JP17K19779), and a grant from the Takeda Science Foundation.

\section{Availability of data and materials}

The datasets used and/or analyzed during the current study are available from the corresponding author on reasonable request.

\section{Authors' contributions}

MC was a major contributor in performing experiments and writing the manuscript. IN, HU, and HK helped perform experiments. MC was the leader of this study. All authors read and approved the final manuscript.

\section{Ethics approval and consent to participate}

Not applicable.

\section{Patient consent for publication}

Not applicable.

\section{Competing interests}

The authors declare that they have no competing interests.

\section{References}

1. Lee RC, Feinbaum RL and Ambros V: The C. elegans heterochronic gene lin-4 encodes small RNAs with antisense complementarity to lin-14. Cell 75: 843-854, 1993.

2. Chiba M, Monzen S, Iwaya C, Kashiwagi Y, Yamada S, Hosokawa Y, Mariya Y, Nakamura T and Wojcik A: Serum miR-375-3p increase in mice exposed to a high dose of ionizing radiation. Sci Rep 8: 1302, 2018.

3. Wen Y, Han J, Chen J, Dong J, Xia Y, Liu J, Jiang Y, Dai J, Lu J, Jin $\mathrm{G}$, et al: Plasma miRNAs as early biomarkers for detecting hepatocellular carcinoma. Int J Cancer 137: 1679-1690, 2015.

4. Ben-Dov IZ, Tan YC, Morozov P, Wilson PD, Rennert H, Blumenfeld JD and Tuschl T: Urine microRNA as potential biomarkers of autosomal dominant polycystic kidney disease progression: Description of miRNA profiles at baseline. PLoS One 9: e86856, 2014.

5. Akers JC, Ramakrishnan V, Kim R, Phillips S, Kaimal V, Mao Y, Hua W, Yang I, Fu CC, Nolan J, et al: miRNA contents of cerebrospinal fluid extracellular vesicles in glioblastoma patients. J Neurooncol 123: 205-216, 2015.

6. Rubio M,Bustamante M,Hernandez-Ferrer C, Fernandez-Orth D, Pantano L, Sarria Y, Piqué-Borras M, Vellve K, Agramunt S, Carreras $\mathrm{R}$, et al: Circulating miRNAs, isomiRs and small RNA clusters in human plasma and breast milk. PLoS One 13: e0193527, 2018.

7. Wang Z, Zhang J, Wei W, Zhou D, Luo H, Chen X and Hou Y: Identification of saliva using MicroRNA biomarkers for forensic purpose. J Forensic Sci 60: 702-706, 2015.

8. Molina-Pinelo S, Suárez R, Pastor MD, Nogal A, Márquez-Martín E, Martín-Juan J, Carnero A and Paz-Ares L: Association between the miRNA signatures in plasma and bronchoalveolar fluid in respiratory pathologies. Dis Markers 32: 221-230, 2012.

9. Záveský L, Jandáková E, Weinberger V, Minář L, Hanzíková V, Dušková D, Drábková LZ, Svobodová I and Hořínek A: Ascites-derived extracellular microRNAs as potential biomarkers for ovarian cancer. Reprod Sci: Jan 1, 2018 (Epub ahead of print).

10. Han HS, Yun J, Lim SN, Han JH, Lee KH, Kim ST, Kang MH, Son SM, Lee YM, Choi SY, et al: Downregulation of cell-free miR-198 as a diagnostic biomarker for lung adenocarcinoma-associated malignant pleural effusion. Int J Cancer 133: 645-652, 2013.

11. Taylor DD and Gercel-Taylor C: MicroRNA signatures of tumor-derived exosomes as diagnostic biomarkers of ovarian cancer. Gynecol Oncol 110: 13-21, 2008.

12. Chiba M, Kimura M and Asari S: Exosomes secreted from human colorectal cancer cell lines contain mRNAs, microRNAs and natural antisense RNAs, that can transfer into the human hepatoma HepG2 and lung cancer A549 cell lines. Oncol Rep 28: $1551-1558,2012$.

13. Xu R, Greening DW, Zhu HJ, Takahashi N and Simpson RJ: Extracellular vesicle isolation and characterization: Toward clinical application. J Clin Invest 126: 1152-1162, 2016.

14. Wagner J, Riwanto M, Besler C, Knau A, Fichtlscherer S, Röxe T, Zeiher AM, Landmesser U and Dimmeler S: Characterization of levels and cellular transfer of circulating lipoprotein-bound microRNAs. Arterioscler Thromb Vasc Biol 33: 1392-1400, 2013.

15. Wang K, Zhang S, Weber J, Baxter D and Galas DJ: Export of microRNAs and microRNA-protective protein by mammalian cells. Nucleic Acids Res 38: 7248-7259, 2010

16. Kloosterman WP, Lagendijk AK, Ketting RF, Moulton JD and Plasterk RH: Targeted inhibition of miRNA maturation with morpholinos reveals a role for miR-375 in pancreatic islet development. PLoS Biol 5: e203, 2007.

17. Li X: MiR-375, a microRNA related to diabetes. Gene 533: 1-4, 2014.

18. Poy MN, Eliasson L, Krutzfeldt J, Kuwajima S, Ma X, Macdonald PE, Pfeffer S, Tuschl T, Rajewsky N, Rorsman P and Stoffel M: A pancreatic islet-specific microRNA regulates insulin secretion. Nature 432: 226-230, 2004.

19. Eliasson L: The small RNA miR-375-a pancreatic islet abundant miRNA with multiple roles in endocrine beta cell function. Mol Cell Endocrinol 456: 95-101, 2017.

20. Lenzen S: The mechanisms of alloxan-and streptozotocin-induced diabetes. Diabetologia 51: 216-226, 2008.

21. Okusaka T, Ueno H, Morizane C, Kondo S, Sakamoto Y, Takahashi H, Ohno I, Shimizu S, Mitsunaga S and Ikeda M: Cytotoxic chemotherapy for pancreatic neuroendocrine tumors. J Hepatobiliary Pancreat Sci 22: 628-633, 2015. 
22. Latreille M, Herrmanns K, Renwick N, Tuschl T, Malecki MT, McCarthy MI, Owen KR, Rülicke T and Stoffel M: miR-375 gene dosage in pancreatic $\beta$-cells: Implications for regulation of $\beta$-cell mass and biomarker development. J Mol Med (Berl) 93: 1159-1169, 2015.

23. Bathina S, Srinivas N and Das UN: Streptozotocin produces oxidative stress, inflammation and decreases BDNF concentrations to induce apoptosis of RIN5F cells and type 2 diabetes mellitus in Wistar rats. Biochem Biophys Res Commun 486: 406-413, 2017.
24. Erener S, Mojibian M, Fox JK, Denroche HC and Kieffer TJ: Circulating miR-375 as a biomarker of $\beta$-cell death and diabetes in mice. Endocrinology 154: 603-608, 2013.

25. Meyn RE, Stephens LC and Milas L: Programmed cell death and radioresistance. Cancer Metastasis Rev 15: 119-131, 1996.

26. Mathivanan S, Ji H and Simpson RJ: Exosomes: Extracellular organelles important in intercellular communication. J Proteomics 73: 1907-1920, 2010. 